\title{
Kinetics of Fast Haemoglobin in Diabetic Rats
}

\author{
B. Vialettes ${ }^{1}$, L.Vovan ${ }^{2}$, M.C.Simon ${ }^{1}$, V.Lassmann ${ }^{1}$, E. Altomare ${ }^{1}$, and Ph. Vague ${ }^{1}$ \\ ${ }^{1}$ Department of Internal Medicine, Hôpital Universitaire Michel Levy and ${ }^{2}$ Haemoglobinopathy and Paediatric Haematology Laboratory, \\ Hopital Universitaire La Timone, Marseille, France
}

\begin{abstract}
Summary. This study was designed to examine the appearance and disappearance kinetics of glycosylated haemoglobin during abrupt changes of blood glucose in the rat. The concentration of the fast haemoglobin component, which has similar chromatographic and electrophoretic profiles to human haemoglobin $\mathrm{A}_{1}$, was measured after the induction of diabetes by streptozotocin and its cure by syngeneic intraportal islet transplantation. Fast haemoglobin was increased in 12 diabetic rats compared with 22 controls $(15.8 \pm 0.8$ versus $8.2 \pm 0.3 \%$, mean \pm SEM). In a group with mild diabetes $(n=8$, blood glucose $<22 \mathrm{mmol} / \mathrm{l})$, fast haemoglobin rose to $13.7 \pm 1.0 \%$ by week 8 . In a group with severe diabetes $(n=4$, blood glucose $>22 \mathrm{mmol} / \mathrm{l}$ ), fast haemoglobin rose more quickly (in 3 weeks) to a higher level $(18.2 \pm 3.3 \%)$ and changed little thereafter. This suggests a saturable system in which the rate of increase and final value depend upon the degree of hyperglycaemia. After islet transplantation, fast haemoglobin returned to normal in 4 weeks $(n=5,17.6 \pm 1.4$ to $9.4 \pm 0.9 \%)$. This delay is shorter than expected from the red cell lifespan (around 60 days), suggesting that haemoglobin glycosylation may be partly reversible. These results suggest that in unstable diabetes the interpretation of haemoglobin $A_{1}$ levels is not as simple as was supposed previously.
\end{abstract}

Key words: Glycosylated haemoglobin, streptozotocin diabetes, islet transplantation, rat.

Increase of haemoglobin $\mathrm{A}_{1 \mathrm{c}}\left(\mathrm{Hb}_{1 \mathrm{c}}\right)$ in diabetic patients was first described by Rahbar et al. [21] and later linked to hyperglycaemia by Trivelli et al. [27]. There is convincing evidence that glycosylation of $\mathrm{HbA}$ to form $\mathrm{HbA}_{1 \mathrm{c}}$ is secondary to hyperglycaemia and occurs during the entire erythrocyte lifespan $[2,5,6,24]$. Accordingly, $\mathrm{HbA}_{1}\left(\mathrm{HbA}_{1(\mathrm{a}+\mathrm{b}+\mathrm{c})}\right)$ determinations have been proposed as a means of evaluating blood glucose control over a prolonged period of time [7,9, $16,19]$. Unfortunately, despite clinical studies [3, 4, 28], the kinetics of $\mathrm{HbA}_{1}$ level during abrupt changes of diabetic control remain unknown.

In an attempt to elucidate this point, an experimental rat model was designed to achieve successively the rapid induction of hyperglycaemia, stable sustained diabetes, and rapid normalization of plasma glucose. We have studied a fast minor haemoglobin component in rats which has similar electrophoretic and chromatographic profiles to human $\mathrm{HbA}_{1}$. The animals were rendered diabetic by streptozotocin and subsequently cured by intraportal islet transplantation.

\section{Material and Methods}

The animals used were female inbred Lewis rats (CNRS Centre de Sélection et d'Elevage d'Animaux de Laboratoire, Orléans) weighing $170-210 \mathrm{~g}$ at the beginning of experiment.

Diabetes was induced by IV injection of $65 \mathrm{mg} / \mathrm{kg}$ streptozotocin (Sigma) in $0.005 \mathrm{~mol} / 1$ citrate buffer ( $\mathrm{pH} 4.5$ ). Eighteen rats were injected. No death occurred. Four animals did not become diabetic. Fourteen became diabetic and of them 12 were followed in this study. Severe diabetes was defined as a mean plasma glucose above $22 \mathrm{mmol} / 1(n=4)$ during follow-up in any animal. Mild diabetes was taken as a mean plasma glucose between 11 and $22 \mathrm{mmol} / \mathrm{l}(n=8)$.

Islets of Langerhans were isolated from rats as described by Lacy and Kostianowsky [17]. The donor pancreases were distended in vivo by Hanks' balanced salt solution ( $\mathrm{pH} 7.4$ ), removed, minced and digested with $15 \mathrm{mg}$ of collagenase (type IV, Worthington Biochemicals) for every two pancreases for 5-9 min with hand shaking in a waterbath at $37^{\circ} \mathrm{C}$. After two washes in Hank's solution, the islets were counted and hand-picked under a dissecting microscope. For transplantation, 500-1000 islets were slowly embolized into the liver by infusion into a mesenteric vein tributary of the portal vein under ether anaesthesia.

Blood $(500 \mu \mathrm{l})$ was collected into heparinized capillary tubes from a tail vein of non-fasting normal or diabetic rats and was microfuged (Eppendorf microfuge) for $2 \mathrm{~min}$. A $20 \mu \mathrm{l}$ aliquot of plasma was kept frozen at $-20^{\circ} \mathrm{C}$ for subsequent glucose assay (glucose oxidase method, peroxidase-glucose oxidase diagnostica, Roche). The remaining plasma was discarded and the cells were washed three times in $0.154 \mathrm{~mol} / 1$ saline. Erythrocytes were haemolysed by the addition of two volumes of distilled water and two 


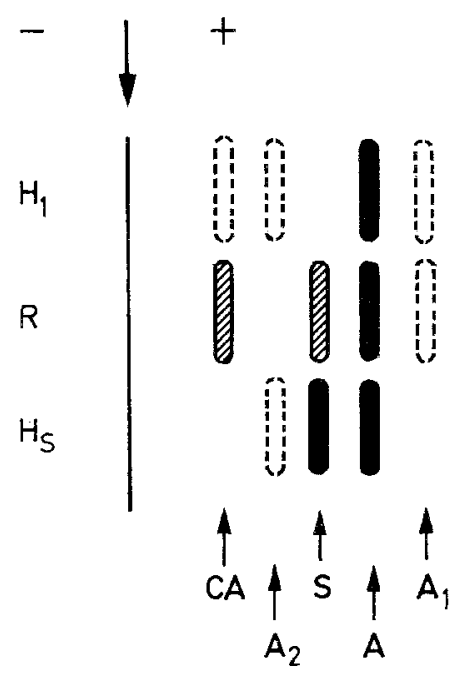

Fig. 1. Electrophoretic profiles of normal man $\left(\mathrm{H}_{1}\right)$ diabetic rat $(R)$ and sickle-cell disease $\left(H_{S}\right)$ haemolysates. ( $C A$ : carbonic anhydrase; $A_{2}$ : $\mathrm{HbA}_{2} ; S: \mathrm{HbS} ; A: \mathrm{HbA} ; A_{1}: \mathrm{HbA}_{1}$ and fast $\left.\mathrm{Hb}\right)$
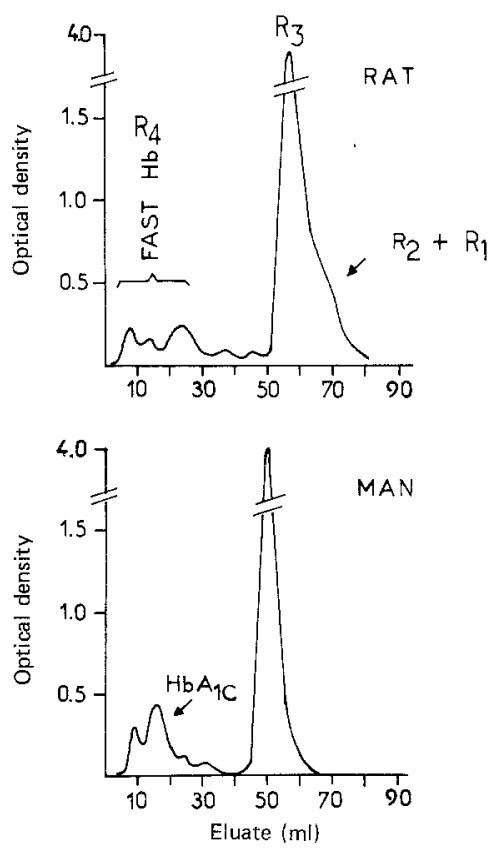

Fig. 2. Chromatographic profile on cation exchange resin of human and rat haemolysates (Symbols are described in materials and methods)

drops of toluene. After vortex mixing the blood was kept for one night at $4{ }^{\circ} \mathrm{C}$. The solution was then spun at $10000 \mathrm{rev} . / \mathrm{min}$ for 1 min.

Electrophoretic isolation of haemoglobin fractions was done on cellulose acetate (cellogel $2.5 \times 17 \mathrm{~cm}$ band) in Tris-EDTA-borate buffer (pH 9.0) under 200 volts for $2 \mathrm{~h}$. Bands were stained after migration by amido-Schwartz colouration. Fractions were then located, cut out and dissolved in acetic acid 80\% (v/v). Optical density (OD) was read at $625 \mathrm{~nm}$. Four main fractions could be isolated from haemolysate by this procedure (Fig. 1). The major component, R3, migrated as human $\mathrm{HbA}$ and represented approximately $50 \%$ of total $\mathrm{Hb}$. R2 migrated coincidently with human $\mathrm{HbS}$ of sicklecell disease and $\mathrm{R} 1$ as carbonic anhydrase. $\mathrm{R} 2$ and $\mathrm{R} 1$ represented about $45 \%$ of whole $\mathrm{Hb}$. Fast $\mathrm{Hb}$ (R4) migrated as human glycosylated $\mathrm{Hb}$ and its level was determinated by the following calculation:
Fast $\mathrm{Hb}=\frac{\mathrm{OD} \mathrm{Hb} \mathrm{R} 4}{\mathrm{OD}(\mathrm{Hb} \mathrm{R} 1+\mathrm{R} 2+\mathrm{R} 3+\mathrm{R} 4)} \times 100$

Reproducibility of fast $\mathrm{Hb}$ assay was tested on duplicated electrophoresis of ten rat haemolysates. Coefficient of intra-assay variation was $2.2 \%$.

The diabetic rat and human haemolysates were also submitted to ion exchange chromatography on a Bio-Rex column (Bio-Rex 70, Pharmacia) as described by Trivelli et al. [27](Fig.2) and isoelectric focussing as described by Beccaria et al. [1]. Both techniques isolated a fast rat $\mathrm{Hb}$ fraction which had a migration profile similar to human $\mathrm{HbA}_{1}$. We assume that this fast fraction separated by electrophoresis is an analogue of human $\mathrm{HbA}_{1}$.

Student's t-test and Pearson's coefficient of correlation were used for statistical analysis. Results are presented as mean \pm SEM.

\section{Results}

\section{Fast Haemoglobin in Normal and Diabetic Rats}

In 22 normal rats mean non-fasting plasma glucose level was $5.9 \pm 0.2 \mathrm{mmol} / 1$ and fast $\mathrm{Hb} 8.2 \pm 0.3 \%$. In contrast in 12 rats in whom diabetes had been established 8 weeks previously, the mean plasma glucose was $21.7 \pm 0.8 \mathrm{mmol} / \mathrm{l}$ and fast $\mathrm{Hb} 15.8 \pm 0.8 \%$. These two populations were statistically different for both parameters $(p<0.001)$.

\section{Correlation Between Plasma Glucose and Fast Haemoglobin Level}

Sixty blood samples were collected from 12 diabetic animals regardless of the date of streptozotocin injection (Fig. 3). A correlation was found between the plasma glucose and fast $\mathrm{Hb}$ level $(r=0.30, p<0.05)$. When samples collected before, 20 days and $50-60$ days after streptozotocin injection were considered separately, a statistically significant correlation was found only for the last group $(r=0.58, p<0.05$; Fig.4). 


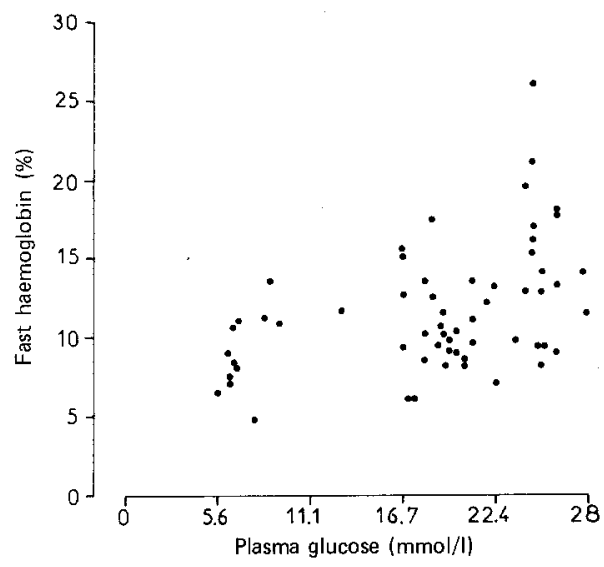

Fig. 3. Fast haemoglobin levels expressed as a function of simultaneous plasma glucose measurement in 60 blood samples regardless of the time of streptozotocin injection
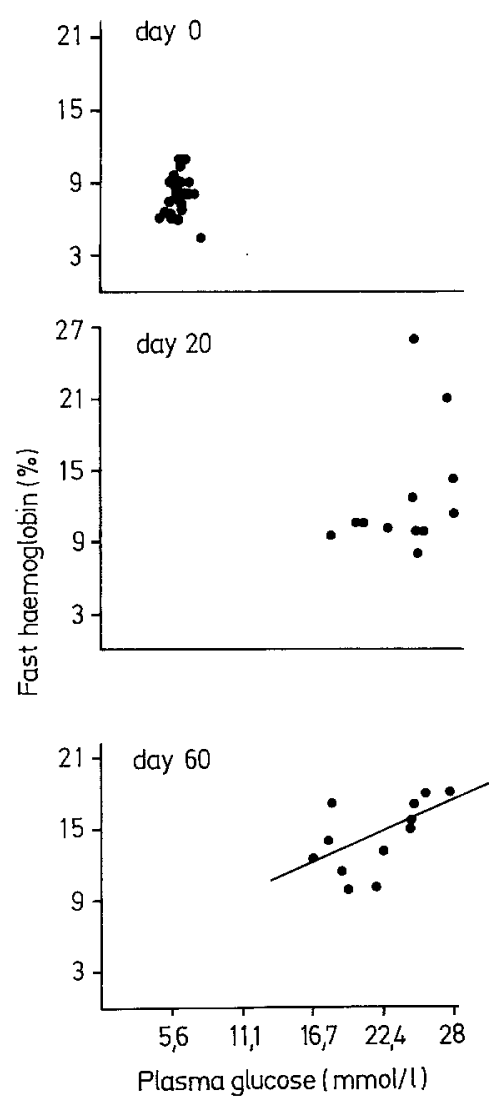

Fig.4. Fast haemoglobin levels expressed as a function of plasma glucose before, 20 and 60 days after streptozotocin injection

\section{Kinetics of Fast Haemoglobin Changes After Induction of Diabetes by Streptozotocin}

Two groups of diabetic rats were isolated according to severity of hyperglycaemia (Fig. 5): group 1 with severe diabetes and group 2 with mild diabetes. In the first group stable hyperglycaemia was established by day 5 following the streptozotocin injection (mean
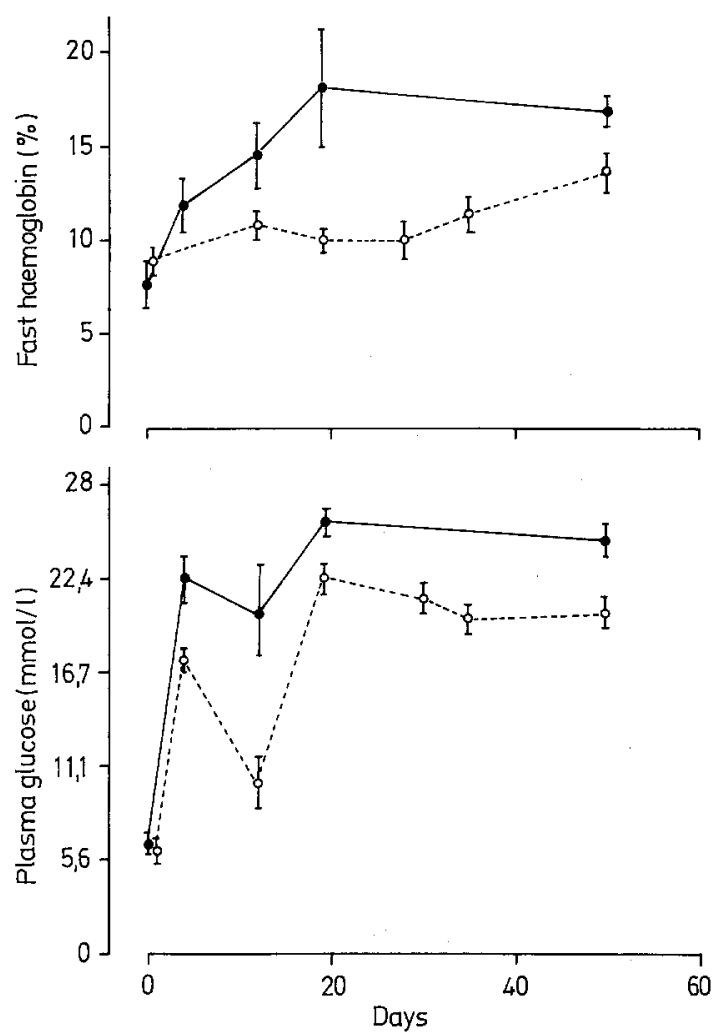

Fig. 5. Changes in fast haemoglobin levels and plasma glucose concentrations after streptozotocin injection (day 0$)$ in mild (O...-O, $n=8)$ and severe $(\bullet-n=4)$ diabetes (mean \pm SEM)

$25.9 \pm 0.8 \mathrm{mmol} / \mathrm{l})$. In the second group the rise in plasma glucose concentration was less regular and led to a lower level $(20 \pm 2.2 \mathrm{mmol} / \mathrm{l})$.

The mean plasma glucose level was significantly different in the two groups $(p<0.005)$. Fast $\mathrm{Hb}$ changes followed those of plasma glucose with different kinetics in each group. In group 1 , fast $\mathrm{Hb}$ level increased rapidly towards a maximum $(18.2 \pm 3.3 \%)$ at 20 days and was no higher $(16.8 \pm 0.7 \%)$ at 50 days. In contrast, in group 2 the increase was more progressive and led to a lower value $(13.7 \pm 1 \%) 60$ days after streptozotocin injection. There was a significant difference between the two groups $(p<0.05)$ in fast $\mathrm{Hb}$ levels at 2 months.

\section{Changes of Fast Haemoglobin After Islet Transplantation}

Five diabetic rats with high plasma glucose and fast $\mathrm{Hb}$ levels sustained for a least 2 weeks $(24.7 \pm$ $1.4 \mathrm{mmol} / \mathrm{l}$ and $17.6 \pm 1.4 \%$, respectively) were transplanted intraportally with islets of Langerhans isolated from adult syngeneic donors. Patterns of plasma glucose and fast $\mathrm{Hb}$ changes are represented in Figure 6. Plasma glucose dropped rapidly by the day after transplantation and became normal between weeks 2 and 3. Fast $\mathrm{Hb}$ levels diminished more slow- 


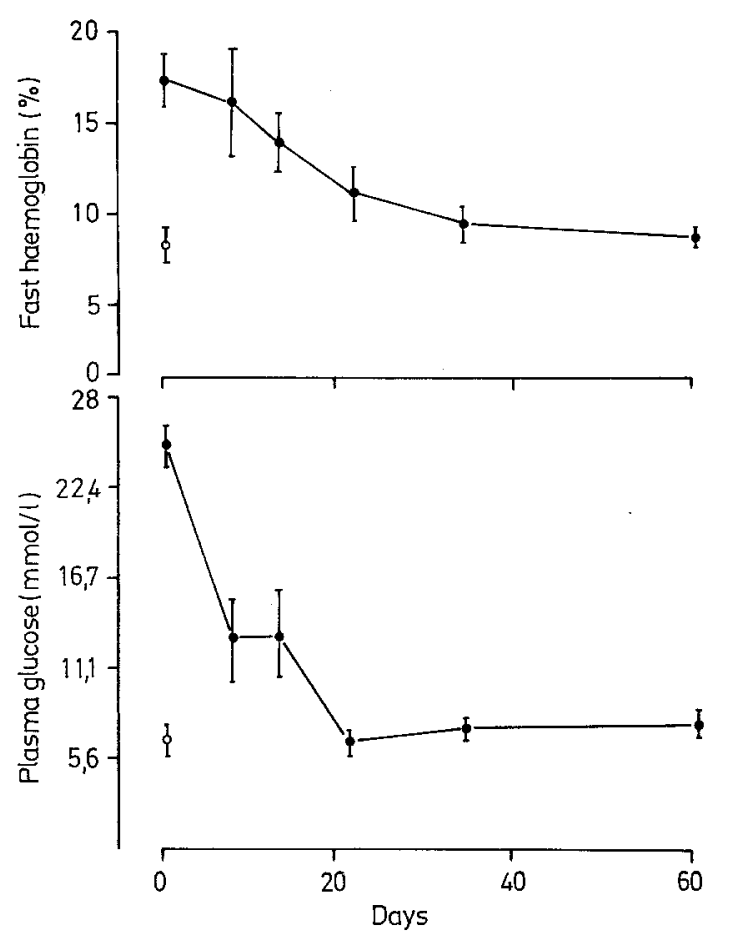

Fig. 6. Changes in fast haemoglobin levels and plasma glucose concentrations after syngeneic islet transplantation (day 0 ) in five diabetic rats (- $\bullet$ ). The open circles indicate values in a series of normal rats (mean \pm SEM)

ly, became comparable with non-diabetic values about 5 weeks after transplantation and thereafter remained stable throughout the observation period of 60 days.

\section{Discussion}

Although extrapolation of results from animal experiments to man requires caution, some similarities exist between our animal model and human diabetes. Rat fast $\mathrm{Hb}$ seems to be analogous to human $\mathrm{HbA}_{1}$ on both chromatographic and electrophoretic study. The increase in fast $\mathrm{Hb}$ induced by hyperglycaemia is an additional argument in favour of similarities in structure and glycosylation. The lifespan of rat erythrocytes is not established but results of isotopic studies range between 45 and 70 days with an average of 60 days $[8,22]$. Diabetes induced by beta-cytotoxic drugs in rats displays the same metabolic and structural features observed in human diabetes, including insulin deficiency [11, 22], hyperglucagonaemia [12], hypertriglyceridaemia [23] and glomerulopathy [18].

Koenig et al. $[14,15]$ have studied other animal models from which an analogue of human $\mathrm{HbA}_{\mathrm{lc}}$ has been isolated, These include C57B1/Ksj mice, among which bearers of the $d b / d b$ gene are spontaneously diabetic, and mice rendered diabetic by the adminis- tration of the B cell-cytotoxic drugs, alloxan and streptozotocin. Studies by these authors in chemically induced diabetes suggested that the $\mathrm{HbA}_{1 \mathrm{c}}$ levels, although increased in the diabetic population, did not correlate with either the degree of hyperglycaemia or the duration of diabetes. In contrast, our results show that fast $\mathrm{Hb}$ changes in the diabetic rat depend on both the plasma glucose level and the duration of hyperglycaemia, at least in the early stages. Hyperglycaemia induced by streptozotocin injection caused a progressive rise in fast $\mathrm{Hb}$ levels over the succeeding weeks. The degree of hyperglycaemia seemed to act more upon the speed of formation of fast $\mathrm{Hb}$ than upon its final level. A maximum value of fast $\mathrm{Hb}$ was obtained by week 3 in the group with severe diabetes, whereas in the group with mild diabetes the fast $\mathrm{Hb}$ level was still rising up to 8 weeks after streptozotocin. In $d b / d b$ mice studied by Koenig et al. [15], $\mathrm{HbA}_{1}$ rose in parallel with the plasma glucose from 11 to $40 \mathrm{mmol} / 1$ with a delay of 4 weeks.

The rapidity of fast $\mathrm{Hb}$ formation and the sustained high values after the first month in our group 1 rats and in mice [15] do not agree with the kinetics deduced from the persistence of a hypothetical glycosylation throughout the entire erythrocyte lifespan. These results suggest a saturation of glycosylation beyond a certain value. This saturation level could be reached sooner or later depending on the degree of hyperglycaemia. This phenomenon could explain the lack of difference in $\mathrm{HbA}_{1}$ level between severely and mild diabetic mice found by Koenig et al. [15]. Saturable glycosylation of $\mathrm{HbA}$ has also been suspected in man by Graf et al. [10]. Clinical studies by Dunn et al. [4] and Vague et al. [28] have shown that in insulin treated diabetic patients, $\mathrm{HbA}_{1}$ correlated well with the last month's glycosuria but less well with those of the two preceding months.

The second part of this work confirmed the ability of syngeneic islet transplantation to reverse the metabolic consequences of chemically induced diabetes $[13,20,25,29,30]$. Islet transplantation also prevents the development of specific glomerular lesions of diabetes in the rat [18]. This study shows that rapid normalization of the $\mathrm{HbA}_{1}$ analogues is another feature of this treatment. The rate of change of fast $\mathrm{Hb}$ was again more rapid than expected. The short delay of 5 weeks necessary to achieve normalization of fast $\mathrm{Hb}$ does not agree with the hypothetical very slow reversibility of haemoglobin glycosylation described by Fluckiger and Winterhalter in human eythrocytes in vitro [6]. A simple progressive disappearance of erythrocytes previously exposed to hyperglycaemia would take longer to normalize $\mathrm{HbA}_{1}$. Clinical studies are in agreement with the results presented here. In cases of remission of juvenile diabetes, Ditzel and Kjaergaard [3] and Vague et al. [28] reported that normalization of 
$\mathrm{HbA}_{1}$ occurred by the first month following the return of plasma glucose to normal values. There are two possible explanations for these findings. First the decay curve of glycosylated haemoglobin following normalization of blood glucose would be expected to be sigmoidal since the earliest cells to disappear are the oldest (and hence more glycosylated) ones and the last to go the least glycosylated. The other explanation is that glycosylation of haemoglobin may at least in part be reversible. Svendsen et al. [26] have demonstrated with human $\mathrm{HbA}_{1 \mathrm{c}}$ isolated by chromatography that rapid changes in vivo or in vitro are not related to the stable $\mathrm{HbA}_{1 \mathrm{c}}$ (ketoamine linked glucose), but to reversible adduct of glucose to haemoglobin. Variations of this adduct may, at least in part, account for the rapid decrease in glycosylated haemoglobin found after glucose normalization in both animals and man.

Acknowledgements. The authors are grateful to S. Halimi and J.Celotto for preparation of the manuscript.

\section{References}

1. Beccaria L, Chiumello G, Gianazza E, Lippis B, Righetti PG (1978) Haemoglobin $A_{1 c}$ repartition by isoelectric focussing. Am J Hematol 4: 367-374

2. Bunn HF, Haney DN, Kamin S, Gabbay KH, Gallop PH(1976) The biosynthesis of human haemoglobin $\mathrm{A}_{\mathrm{lc}}$ : slow glycosylation of haemoglobin in vitro. J Clin Invest 57: 1652-1659

3. Ditzel J, Kjaergaard JJ (1978) Haemoglobin $A_{1 c}$ concentrations after initial insulin treatment for newly discovered diabetes. $\mathrm{Br}$ Med J 1: 741-742

4. Dunn PJ, Firoozabadi H, Cole RA, Younger D, Graham CA, Gleason RE, Soeldner JS (1978) Relative influence of remote and proximal glycaemic events on glycosylated haemoglobin $\%$. Diabetes 27:434 (Abstract)

5. Fizgibbons JF, Koler RD, Jones RT (1976) Red cell age-related changes of haemoglobin $A_{1 a+b}$ and $A_{1 c}$ in normal and diabetic subjects. J Clin Invest 58: $820-824$

6. Fluckiger R, Winterhaiter $\mathrm{KH}$ (1976) In vitro synthesis of haemoglobin $A_{1 c}$. FEBS Lett 71:356-360

7. Gabbay KH, Hasty K, Breslow JL, Ellison RC, Bunn HF, Gallop PM (1977) Glycosylated haemoglobins and longterm blood glucose control in diabetes mellitus. J Clin Endocrinol Metab 44: 859-864

8. Ganzoni AM (1970) Kinetik und Regulation der ErythrocytenProduktion. Springer, Berlin Heidelberg New-York

9. Gonen B, Rubenstein AH (1978) Haemoglobin $A_{1}$ and diabetes mellitus. Diabetologia 15: 1-8

10. Graf RJ, Halter JB, Porte D (1978) Glycosylated haemoglobin in normal subjects and subjects with maturity onset-diabetes. Evidence for saturable system in man. Diabetes 27:834-839

11. Junod A, Lambert AE, Stauffacher W, Renold AE (1969) Diabetogenic action of streptozotocin: relationship of dose to metabolic response. J Clin Invest 48: 2129-2 139

12. Katsilambros N, Rahman YA, Hinz M (1970) Action of streptozotocin on insulin and glucagon responses of rat islet. Horm Metab Res 2: 268-270

13. Kemp CB, Knight MJ, Scharp DW, Lacy PE, Ballinger WF
(1973) Transplantation of isolated pancreatic islets into the portal vein of diabetic rats. Nature 244: $447-448$

14. Koenig RJ, Cerami A (1975) Synthesis of minor haemoglobin in normal and diabetic mice: A potential model of basement membrane thickening. Proc Natl Acad Sci USA 72:3687-3691

15. Koenig RJ, Araujo DC, Cerami A (1976) Increased haemoglobin $A_{1 c}$ in diabetic mice Diabetes 25: 1-5

16. Koenig RJ, Peterson CM, Jones RL, Saudek C, Lehrman M, Cerami A (1976) Correlation of glucose regulation and haemoglobin $A_{1 c}$ in diabetes mellitus. N Engl J Med 295: 417-420

17. Lacy PE, Kostianowsky M (1967) Method for the isolation of intact islets of Langerhans from rat pancreas. Diabetes 16: 35-39

18. Mauer SM, Sutherland DER, Steffes MW, Leonard RJ, Najarian JS, Michael AF, Brown DM (1974) Pancreatic transplantation. Effects on the glomerular lesions of experimental diabetes in the rat. Diabetes 23:748-753

19. Paulsen EP, Koury M (1977) Haemoglobin $A_{1 c}$ level in insulindependent and independent diabetes mellitus. Diabetes 26 : 890-896

20. Pipeleers-Marichal MA, Pipeleers DC, Cutler J, Lacy PE, Kipnis DM (1976) Metabolic and morphologic studies in intraportal-islet-transplanted rats. Diabetes 25: 1041-1051

21. Rahbar S, Blumenfeld O, Ranney HM (1969) Studies of an unusual haemoglobin in patients with diabetes mellitus. Biochem Biophys Res Commun 36: 838-843

22. Schalm OW (1965) Veterinary hematology. Lea Lebiger, Philadelphia

23. Schnatz JD, Formaniak JM, Chlouverakis C (1972) The origin of hypertriglyceridaemia in streptozotocin diabetics rats. Diabetologia 8: 125-130

24. Spicer KM, Allen RC, Hallet D, Buse MG (1979) Synthesis of haemoglobin $A_{1 c}$ and related minor haemoglobin by erythrocytes: in vitro study of regulation. J Clin Invest 64: 40-48

25. Steffes MW, Sutherland DER, Mauer SM, Leonard RJ, Najarian JS, Brown DM (1975) Plasma insulin and glucose levels in diabetic rats prior to and following islet transplantation. $\mathrm{J} \mathrm{Lab}$ Clin Med 85:75-81

26. Svendsen PAA, Christiansen IS, Søegaard U, Welinder BS, Nerup J (1980) Rapid changes in chromatographically determined haemoglobin $\mathrm{A}_{1 \mathrm{c}}$ induced by short-term changes in glucose concentration. Diabetologia 19:130-136

27. Trivelli LA, Ranney HM, Lai HT (1971) Haemoglobin components in patients with diabetes mellitus. $\mathrm{N}$ Engl J Med 284: 353-357

28. Vague PH, Vovan L, Vialettes B, Boustiere C, Serin N (1979) Concentration sanguine en hémoglobine glycosylée $\left(A_{1 c}\right)$, indice du contrôle du diabète dans le mois précédent. Nouv Presse Med 8: 491-494

29. Vialettes B, Sutherland DER, Matas AJ, Payne WD, Najarian JS (1979) Amelioration of streptozotocin induced diabetes in rats. Effect of islet isografts on plasma lipids and other metabolic abnormalities. Metabolism 28: 489-494

30. Ziegler MN, Reckard CR, Barker CF (1974) Long term metabolic and immunological consideration in transplantation of pancreatic islets. J Surg Res 16:575-581

Received: 26 February 1980

and in revised form: 23 December 1981

Dr. Bernard Vialettes

Service de Medecine Interne

Hôpital Universitaire Michel Levy

84 a Rue de Lodi

13281 Marseille, France 